\title{
Composite Hyaluronate-Type I Collagen-Fibrin Scaffold in the Therapy of Osteochondral Defects in Miniature Pigs
}

\author{
E. FILOVÁ ${ }^{1,2}$, M. RAMPICHOVÁ ${ }^{1,2}$, M. HANDL ${ }^{3}$, A. $_{\text {LYTVYNETS }}^{4}$, R. \\ HALOUZKA $^{5}$, D. USVALD ${ }^{6}$, J. HLUČILOVÁ ${ }^{6}$, R. PROCHÁZKA ${ }^{6}, \mathrm{M}$.
}

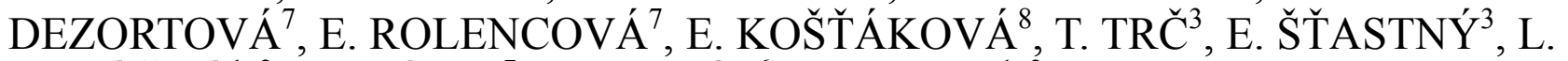
KOLÁČNÁ $^{1,2}$, M. HÁJEK ${ }^{7}$, J. MOTLÍK $^{6}$, E. AMLER ${ }^{1,2}$

${ }^{1}$ Institute of Experimental Medicine of the Academy of Sciences of the Czech Republic, Prague,

${ }^{2}$ Institute of Biophysics, Second Faculty of Medicine, Charles University, Prague, ${ }^{3}$ Orthopedic Clinic, University Hospital Motol, Prague, ${ }^{4}$ Institute of Physiology of the Academy of Sciences of the Czech Republic, Prague, ${ }^{5}$ Institute of Pathological Morphology, Faculty of Veterinary Medicine, University of Veterinary and Pharmaceutical Sciences, Brno, ${ }^{6}$ Institute of Animal Physiology and Genetics of the Academy of Sciences of the Czech Republic, Liberchov, ${ }^{7}$ MR-Unit, ZRIR, Institute for Clinical and Experimental Medicine, Prague, ${ }^{8}$ Technical University of Liberec, Faculty of Textile Engineering, Liberec, Czech Republic

Received May 23, 2007

Accepted May 29, 2007

On-line available May 31, 2007

\begin{abstract}
Summary
The potential of novel scaffold containing sodium hyaluronate, type I collagen, and fibrin was investigated in the regeneration of osteochondral defects in miniature pigs. Both autologous chondrocyte-seeded scaffolds and non-seeded scaffolds were implanted into two defects located in the non-weight-bearing zone of the femoral trochlea (defect A was located more distally and medially, defect B was located more proximally and laterally). Control defects were left untreated. Twelve weeks after the operation, the knees were evaluated in vivo using MRI. Six months after the implantation, the defects were analyzed using MRI, histological, and immunohistochemical analysis. In the A defects of chondrocyte-seeded scaffold group, hyaline cartilage and fibrocartilage was formed, containing type II collagen, acidic and neutral glycosaminoglycans while the non-seeded scaffold group was predominantly filled with fibrocartilage. Defects in the control group were predominantly filled with fibrous tissue. Histomorphometric analysis of photomicrographs revealed a significantly higher amount of hyaline cartilage in the cell-seeded scaffold group in A defects than in other groups. Both scaffold groups in A defects showed significantly less fibrous tissue than cell-seeded defects B and the control group. Both histological and MRI analysis proved that the novel composite scaffold has a potential to regenerate osteochondral defects within six months.
\end{abstract}

\section{Key words}

Osteochondral defect $\bullet$ Fibrin $\bullet$ Autologous chondrocytes $\bullet$ Cartilage regeneration 


\section{Introduction}

Isolated chondral or osteochondral defects, when left untreated, fail to heal. Moreover, large defects can progress to symptomatic degeneration of the joint. Therefore, the treatment of selected isolated defects may prevent or delay the development of osteoarthritis. Standard surgical techniques, such as debridement, drilling or microfracturing of subchondral bone, osteotomy, mosaicplasty, transplantation of autographs from non-weight bearing zone into former defect area, and soft tissue grafts, such as perichondrial, periosteal flap, joint capsule, or fascia have the potential to stimulate formation of new articular surface, and may decrease symptoms and improve the joint function (Niedermann et al. 1985, Hoikka et al. 1990, Buckwalter and Mankin 1998a). However, they are not able to restore normal articular cartilage (Buckwalter and Mankin 1998a).

One of the modern techniques involves autologous chondrocytes injected into the defect that is covered by periosteal flap sealed with fibrin glue (Brittberg et al. 1994, Breinan et al. 1997, 2001). However, in animal models, a positive effect of ACI was observed only three months after the implantation (Breinan et al. 2001), but no effect was observed after 12 and 18 months (Breinan et al. 1997). That may be explained by the lack of retention of the cells in the defect due to possible displacement of the periosteal flap, and the location of the defect.

The second generation of ACI technique (or ACT) involves autologous chondrocytes injected under a three-dimensional biodegradable scaffold such as collagen bilayer membrane (Chondro-Gide ${ }^{\mathrm{TM}}$ membrane, Geistlich Biomaterials) (Marlovits et al. 2006).

The third generation of ACT is based on autologous chondrocyte-seeded biomaterials as cell carriers (MACT). Hyaluronan derivative fleece, typeI/III collagen membrane, and polylactin and polyglactin are intensively examined in clinical studies (Pavesio et al. 2003, Marlovits et al. 2005, Trattnig et al. 2005, Marlovits et al. 2006). In comparison with the second generation of ACT, this technique allows chondrocytes to redifferentiate and to produce their own extracellular matrix. Subjective and objective improvement has been observed in $76 \%$ to $100 \%$ of patients. In spite of these promising results, incomplete filling (Trattnig et al. 2005) and rare detachment of the scaffold have occurred (Marlovits et al. 2005).
Hydrogels mimic the natural highly hydrated cartilage that contains above $90 \%$ of water (Buckwalter and Mankin 1998b). They include naturally derived biopolymers, such as collagen, fibrin, chitosan, agarose, alginate, hyaluronic acid derivatives (Drury and Mooney 2003, Ng et al. 2005), or synthetic polymers, such as polyvinyl alcohol, polyethylene oxide, and polyethylene glycol (Bryant and Anseth 2002, Kobayashi et al. 2003). Crosslinked hydrogels (Bryant and Anseth 2002), or porous scaffolds prepared from hydrogels by crosslinking and/or by freeze-drying exhibit increased stiffness and reduced degradation velocity (Chang et al. 2003). They allow preparing scaffolds of variable composition, biological, and biomechanical properties, especially when they are combined with other hydrogels, woven or nonwoven scaffolds, and other polymer scaffolds (Minoura et al. 1998). In our previous study, we developed a novel composite scaffold consisting of sodium hyaluronate, type I collagen and fibrin, and proved its ability to regenerate osteochondral defects in rabbits within six weeks. The purpose of this study was to prove the longtime efficacy of the same scaffold in cartilage regeneration in miniature pigs.

\section{Methods}

\section{Animal care}

The investigation was approved by the Expert Committee of the Institute of Physiology, Academy of Sciences, Prague, and conformed with the Czech Animal Protection Law № 246/92. Animals were premedicated with intramuscular $2.0 \mathrm{mg} / \mathrm{kg}$ azaperonum and $1 \mathrm{mg}$ Atropin Biotika pro toto in the same syringe (posterior thigh - semitendinous and semimembranous muscles). Marginal auricular vein was used for anesthetic induction drugs (ketamine $20 \mathrm{mg} / \mathrm{kg}$ ). Animals were intubated with $2.5 \mathrm{~F}$ tracheal tube without cuff. Anesthesia was maintained with $1.5 \%$ isoflurane at $2 \mathrm{l} / \mathrm{min}$ constant flow. During in vivo MRI measurement the general anesthesia was done by continual infusion into marginal auricular vein with ketamine $(20 \mathrm{mg} / \mathrm{kg})$.

\section{Chondrocyte isolation and cell culture}

Small pieces of cartilage were taken from the left femoral trochlea of three miniature pigs (total of nine miniature pigs) under general anesthesia. After enzymic digestion, chondrocytes were collected and cultured for 14 days in Iscove's Modified Dulbecco's Medium supplemented with $15 \%$ fetal bovine serum (FBS), $3 \mathrm{~g} / 1$ 
$\mathrm{NaHCO}_{3}, 100 \mathrm{IU} / \mathrm{ml}$ penicillin, $100 \mu \mathrm{g} / \mathrm{ml}$ streptomycin, $4 \mathrm{mM}$ L-glutamine, $20 \mu \mathrm{g} / \mathrm{ml}$ L-ascorbate-2-phosphate sesquimagnesium salt, $50 \mathrm{ng} / \mathrm{ml}$ insulin-like growth factor (IGF-I, human recombinant (hr), Sigma), $10 \mathrm{ng} / \mathrm{ml}$ basic fibroblast growth factor (bFGF, hr, Roche Applied Science), and $1 \mathrm{ng} / \mathrm{ml}$ transforming growth factor $\beta 2$ (TGF- $\beta 2$ from porcine platelets, Sigma-Aldrich). During the subsequent 9 days the cells were cultured in the same medium but containing $10 \%$ FBS. The cells were incubated at $37{ }^{\circ} \mathrm{C}$ in a humidified atmosphere with $5 \%$ $\mathrm{CO}_{2}$. The culture was passaged always before confluence was reached and the medium was exchanged every three days.

\section{Scaffold preparation}

The scaffolds were prepared in the wells of a 24well plate at about $4{ }^{\circ} \mathrm{C}$ by mixing $33 \mu \mathrm{l}$ of sodium hyaluronate $(10 \mathrm{mg} / \mathrm{ml}, 1500 \mathrm{kDa}$, kindly provided by CPN, CR) with $49.4 \mu \mathrm{l}$ of $1 \mathrm{mg} / \mathrm{ml}$ type I collagen in 0.1 $\mathrm{M}$ acetic acid (Collagen type I from calf skin, acid soluble, Sigma) and neutralized with $1 \mathrm{M} \mathrm{KOH}$. $66 \mu \mathrm{l}$ of cell suspension $\left(4.3 \times 10^{6}\right.$ chondrocytes $)$ or $66 \mu \mathrm{l}$ of media, respectively, was then added. Into this medium containing five times higher concentrations of growth factors compared to culture medium and $20 \%$ FBS, we added $0.16 \mathrm{ml}$ of Tissucol solution in aprotinin (fibrinogen $70-110 \mathrm{mg} / \mathrm{ml}$, aprotinin 3000 kallidinogenase-inactivator units $/ \mathrm{ml}$ ), and $0.16 \mathrm{ml}$ of thrombin solution $(4 \mathrm{IU} / \mathrm{ml})$ in $\mathrm{CaCl}_{2}(40 \mu \mathrm{mol} / \mathrm{ml}$, Tissucol ${ }^{\circledR}$ Kit, Baxter). Two identical scaffolds were prepared for each animal. The gel was formed at $37{ }^{\circ} \mathrm{C}$. Subsequently, the culture medium was added and the scaffold was placed in an incubator with a humidified atmosphere, $5 \% \mathrm{CO}_{2}$ at $37{ }^{\circ} \mathrm{C}$ for one day.

\section{MRI examination}

Twelve weeks after the implantation, in vivo MRI evaluation of the knees was performed under general anesthesia, euthanasia of miniature pigs was performed twenty-four weeks after the implantation by intravenous anesthetic thiopental overdosing, and the entire knees were evaluated using MRI. MRI examination was performed on a whole-body MR system Siemens Vision 1.5 T (Erlangen, Germany) using a standard CP head coil. Subjects were measured in a supine position with the knee in the middle of the head coil. MR images were obtained in sagittal orientation using T1-weighted spin echo $(\mathrm{TR} / \mathrm{TE}=500 / 12 \mathrm{~ms})$ and FLASH $(\mathrm{TR} / \mathrm{TE}=$ $999 / 11 \mathrm{~ms}$ ) sequence, $\mathrm{FOV}=280 \mathrm{~mm}$, slice thickness 3 $\mathrm{mm}$. The same T1-weighted sequence was repeatedly applied after contrast agent (Gd-DTPA) application.

\section{Histological examination and immunohistochemistry}

Femoral trochleas were taken away and fixed in $10 \%$ phosphate-buffered formalin for $48 \mathrm{~h}$ for histological and immunohistochemical analysis. Briefly, after 48-h fixation, the samples were washed in water and decalcified in $8 \mathrm{M}$ formic acid for seven days. After decalcification, the samples were put into a $5 \%$ sodium sulfate solution for $8 \mathrm{~h}$ and subsequently washed using tap water for $24 \mathrm{~h}$. The samples were embedded in paraffin and $4 \mu \mathrm{m}$ thick sections were stained with hematoxylin-eosin. Staining with Alcian blue at $\mathrm{pH} 2.5$ and the PAS reaction was done to verify acidic and neutral GAG synthesis. The preparations were dehydrated and embedded in Canadian balsam. Immunohistochemical staining was done to identify type II collagen using a monoclonal antibody against type II collagen, clone II-II6B3, obtained from Developmental Studies Hybridoma Bank, University of Iowa, Iowa City. Subsequently, the biotinylated secondary antibody and streptavidin-peroxidase (both Immunotech) were used. Reactions were visualized using the DAB Chromogen Kit (Immunotech). The slides were counterstained with hematoxylin.

\section{Histological and histochemical scoring system}

The repair of osteochondral defects in all groups was compared by the scoring system for histological and histochemical results with maximum 24 points, modified from van Susante et al. (1999). The blinded analysis was performed by two authors.

\section{Histomorphometric analysis}

Histomorphometric analysis of photomicrographs of the histological preparations was performed using several randomly selected areas of each defect (Microscope IX 51, Olympus). The amount of hyaline cartilage, fibrocartilage, and fibrous and/or fibrovascular tissue was measured as their percentage of the total area of defect. Total area of the defect was measured by marking the borders of the defect to the defect base and the adjacent cartilage. The blinded analysis was performed by two authors using software Ellipse (ViDiTo, Kosice, Slovakia). The evaluation of hyaline cartilage, fibrocartilage and fibrous tissue was performed according to Breinan 2001. 


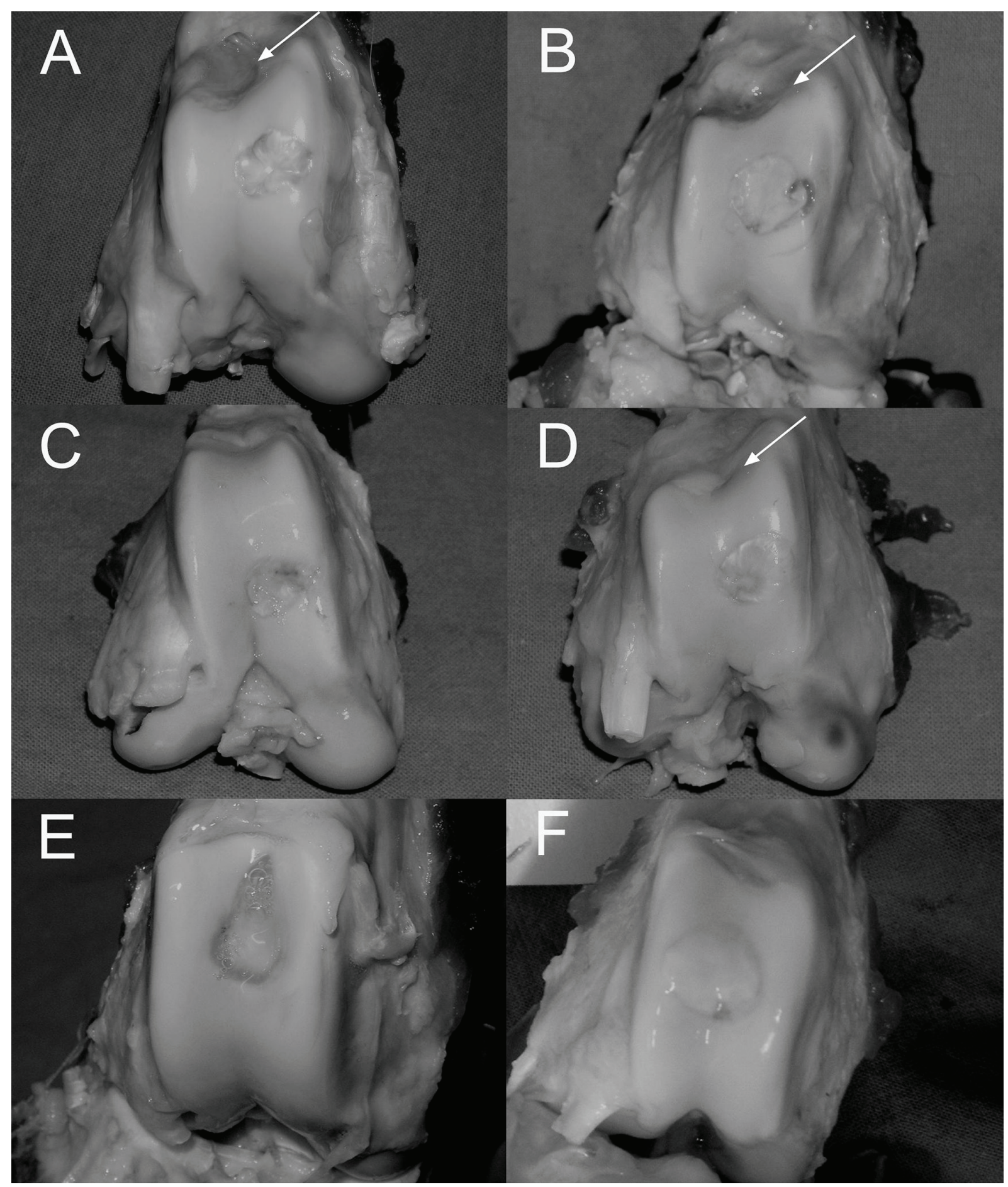

Fig. 1. Femoral trochlea of miniature pigs 24 weeks after the implantation. Defect A was located more distally and medially; defect $B$ was located more proximally and laterally. Arrows show the positions of defect B. (A and B - chondrocyte-seeded scaffold group; C, D non-seeded scaffold group; E, F - control group)

\section{Statistical analysis}

Quantitative data of histomorphometric analysis were presented as mean \pm SEM (standard error of the mean). Statistical analysis was performed using One Way Analysis of Variance (ANOVA) and Student-NewmanKeuls Method. The level of significance was set at 0.05 . Only groups with 3 animals were analyzed.

\section{Results}

\section{Defect simulation and treatment}

Patella was dislocated on the lateral site after medial arthrotomy of the knee-joint. Menisci remained untouched. Two experimental circular lesions were created by a 6-mm (diameter) and 2-mm (depth) drill 
harvester approaching the subchondral bone in the nonweight-bearing zone in the upper part of medial condyle. To follow the complex effect of cell implantation and knee loading for healing processes, two localizations of cartilage lesion were investigated in the present study. Defect A was located more distally and medially (closer to the weight-bearing zone); defect B was located more proximally and laterally, and farther from the nonweight-bearing zone.

The defects were filled with two pieces of scaffold (as sandwich) containing cultured autologous chondrocytes in three animals (chondrocyte-seeded scaffold group), with two pieces of scaffold without cells in three animals (non-seeded scaffold group). In the control group of three animals, defects A were created and left untreated. The scaffolds were glued to the adjacent tissue and subchondral bone with Tissucol ${ }^{\circledR}$ fibrin glue. Wound healing proceeded without any complication in all cases during the whole post-operation period. Miniature pigs were not limited in their movement after surgery.

\section{Macroscopic evaluation}

Chondrocyte-seeded scaffold group. The composite scaffold (hyaluronate/type I collagen/fibrin) seeded with autologous chondrocytes in miniature pigs resulted in almost completely filled defect A after six months. Tissue visually resembled hyaline cartilage (Figs $1 \mathrm{~A}$ and 1B). The surface was predominantly homogeneous; in one animal the medial edge was irregular and incompletely filled with repaired tissue. The contours of the defect were visible. Defects B were partially filled with the white tissue in distal part adjacent to hyaline cartilage. The proximal yellow part adjacent to fibrous tissue (fibrous capsule) was not filled with the tissue and resembled fibrous tissue (Figs 1A and 1B).

Non-seeded scaffold group. Defects A were filled completely with white tissue, and one defect was filled only partially (Figs 1C and 1D). The color and surface were not homogeneous and the repaired tissue partially resembled the adjacent cartilage. Defects B were done in two animals. The defects were partially filled with white tissue; the proximal part of the defect was not filled and resembled fibrous tissue (Fig. 1D).

Control group. The defect was filled in one case and weakly filled in two animals; the color was whiteyellowish with uneven surface and distinct contours (Figs $1 \mathrm{E}$ and $1 \mathrm{~F})$.

\section{Histological and histochemical score}

Structural characteristics of the repaired tissue (Table 1) revealed a higher score in the A defects of chondrocyte-seeded scaffold group (total score - 26, 21, and 23) in comparison with chondrocyte-seeded scaffold in defects B (total score - 16, 9, and 9), and slightly higher than other groups (total score - 16, 19, and 21 of defects A; 19, and 19 of defects B) of non-seeded scaffold group; control group (total score - 13, 14, and 20). Its improvement was observed in all tested parameters. Chondrocyte-seeded scaffold in defects B revealed a lower score than non-seeded scaffold in defect A (total score - 16, 18, and 21).

\section{Histomorphometric analysis}

Defects A of chondrocyte-seeded scaffold group contained significantly more hyaline cartilage than other groups. Non-seeded scaffold in defect A revealed significantly more fibrocartilage compared to chondrocyte-seeded scaffold in defects B. However, both defects B of chondrocyte-seeded scaffold group and control group had significantly more fibrous tissue than both types of scaffolds in defects A. (Table 2)

\section{Magnetic resonance images}

Three months after the implantation, defects A with chondrocyte-seeded scaffolds were well visible with minimal edema in all cases. Joint cartilages were slightly inhomogeneous without signs of synovitis. In the nonseeded scaffold group, defects A were distinct with prominent edema in the adjacent bone; joint cartilage was inhomogeneous. After application of the contrast agent, the tissue saturation was moderate, and predominantly at the basis of the defects. Synovium was slightly thicker with signs of synovitis. Defects in the control group were clearly visible without high edema and rather inhomogeneous. The signal of the defects slightly enhanced after contrast agent application and the basis showed signs of synovitis.

Six months after the implantation, defects A implanted with chondrocyte-seeded scaffolds remained still visible, without signs of edema in the adjacent bone. The joint cartilage was slightly inhomogeneous. In the non-seeded scaffold group, defects A were clearly visible with sclerotic basis that could lead to slower regeneration. Edema decreased and the cartilage remained slightly inhomogeneous. In the controls, the cartilage has become homogeneous, the edema decreased. The defects were not unambiguously differentiated. 
Table 1. Histological and histochemical scoring system, modified from van Susante et al. (1999); (AC, BC - chondrocyte-seeded scaffolds implanted in defects $A$, and B, respectively; A, B - non-seeded scaffolds implanted in defects A, and B, respectively; control defects without treatment)

\section{Characteristic}

AC $\quad$ BC

A B Control

Nature of predominant tissue

Cellular morphology (I)

Hyaline articular cartilage

Incompletely differentiated

Fibrous tissue and bone

Alcian blue staining of the matrix (II)

Normal or near normal

Moderate

Slight

None

Structural characteristics

Surface regularity (III)

Smooth and intact

Superficial horizontal lamination

Fissures, $25-100 \%$ of the thickness

Severe disruption or fibrillation

Structural integrity (IV)

Normal

Slight disruption, including cysts

Severe disintegration

Thickness (V)

$100 \%$ of normal adjacent cartilage

$50-100 \%$ of normal cartilage

$0-50 \%$ of normal cartilage

Bonding to the adjacent tissue (VI)

Bonded at both sides and subchondral bone

Bonded partially

Not bonded

$\begin{array}{llllll}(4) & 2 & 0 & 0 & 0 & 0 \\ (2) & 1 & 0 & 3 & 2 & 1 \\ (0) & 0 & 3 & 0 & 0 & 2 \\ & & & & & \\ (3) & 2 & 0 & 1 & 0 & 0 \\ (2) & 1 & 0 & 2 & 2 & 1 \\ (1) & 0 & 3 & 0 & 0 & 2 \\ (0) & 0 & 0 & 0 & 0 & 0\end{array}$

Freedom from cellular changes of degeneration

(3) $\begin{array}{llllll}3 & 0 & 1 & 2 & 0\end{array}$

(2) $\begin{array}{lllll}0 & 2 & 2 & 0 & 3\end{array}$

(1) $\begin{array}{lllll}0 & 0 & 0 & 0 & 0\end{array}$

(0) $\begin{array}{lllll}0 & 1 & 0 & 0 & 0\end{array}$

(2) 1100000

(1) $\begin{array}{llllll}2 & 2 & 3 & 2 & 3\end{array}$

(0) $\begin{array}{lllll}0 & 1 & 0 & 0 & 0\end{array}$

(2) $\begin{array}{llllll}2 & 0 & 1 & 0 & 0\end{array}$

(1) $\begin{array}{llllll}1 & 3 & 2 & 2 & 3\end{array}$

(0) $\begin{array}{lllll}0 & 0 & 0 & 0 & 0\end{array}$

Hypocellularity (VII)

None

Slight

Moderate

Severe

Chondrocyte clustering (VIII)

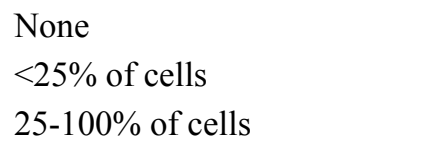

Freedom from degenerative changes in adjacent cartilage (IX)

Normal cellularity, no clusters, normal staining

Normal cellularity, mild clusters, moderate staining

(2) $\begin{array}{llllll}3 & 2 & 3 & 2 & 3\end{array}$

(1) $\begin{array}{lllll}0 & 1 & 0 & 0 & 0\end{array}$

(0) $\begin{array}{lllll}0 & 0 & 0 & 0 & 0\end{array}$

Mild or moderate hypocellularity, slight staining

Severe hypocellularity, poor or no staining

(3)

(2) $\begin{array}{lllll}0 & 1 & 1 & 0 & 0\end{array}$

(1) $\begin{array}{lllll}0 & 1 & 0 & 0 & 2\end{array}$

(0) $\begin{array}{lllll}0 & 0 & 0 & 0 & 0\end{array}$

(2) $\begin{array}{llllll}2 & 1 & 1 & 0 & 2\end{array}$

(1) $\begin{array}{llllll}2 & 1 & 2 & 2 & 1\end{array}$

(0) $\begin{array}{llllll}0 & 1 & 0 & 0 & 0\end{array}$

(3) $\begin{array}{llllll}2 & 0 & 0 & 0 & 1\end{array}$

(2) $\begin{array}{llllll}1 & 3 & 2 & 2 & 2\end{array}$

(1) $\begin{array}{llllll}0 & 0 & 1 & 0 & 0\end{array}$

(0) $\begin{array}{lllll}0 & 0 & 0 & 0 & 0\end{array}$ 
Table 2. Histomorphometric analysis of photomicrographs of the defects. Content of hyaline cartilage, fibrocartilage, and fibrous and/or fibrovascular tissue in the defect was determined as a percentage of the total defect area (mean \pm S.E.M.). (AC, BC - chondrocyteseeded scaffolds implanted in the defects A, and B, respectively, A, and B - non-seeded scaffolds implanted in defect A, and B, respectively, control - defects without treatment)

\begin{tabular}{lccccc}
\hline & AC (\%) & BC (\%) & A (\%) & B (\%) & Control (\%) \\
\hline Hyaline cartilage & $48.72 \pm 17.27$ & 0 & $16.68 \pm 8.92$ & $30.80 \pm 6.03$ & 0 \\
Fibrocartilage & $32.65 \pm 6.14$ & $19.23 \pm 10.39$ & $66.89 \pm 7.41$ & $49.70 \pm 13.46$ & $31.23 \pm 11.94$ \\
$\begin{array}{l}\text { Fibrous/ fibrovascular } \\
\text { tissue }\end{array}$ & $18.63 \pm 11.2$ & $80.77 \pm 10.39$ & $16.43 \pm 14.35$ & $19.50 \pm 19.50$ & $68.77 \pm 11.94$ \\
\hline
\end{tabular}

\section{Histological examination and immunohistochemistry}

Chondrocyte-seeded scaffold group. Defects A were twice thicker than normal cartilage, approaching the subchondral bone (Fig. 2A). Repaired cartilaginous tissue filled the defects; the repaired tissue was slightly disintegrated. The collagen fibers were horizontally oriented on the surface and vertically in the deep part of the defects. All tissues revealed more intense staining of acidic GAGs than neutral GAGs (Figs 2C and 2E). The new repaired tissue was well integrated to both adjacent cartilage and bone. Type II collagen was present in all samples; intense staining was found both in the middle and the deep part of the defects (Fig. 2G). Defects B, however, were filled with fibrovascular and lipid tissue with synovium at the surface (Fig. 2B). Tissue formation was irregular, and PAS-positive substances were present in subchondral bone (Fig. 2D and 2F). In one defect, inflammatory cells were present in the repaired tissue. Type II collagen staining was negative in the repaired tissue (Fig. 2H).

Non-seeded scaffold group. Defects A were flat and filled with mature fibrocartilage or cartilage (Fig. $3 \mathrm{~A}$ ), in one sample with superficial inflammatory infiltration. Alcian-blue- positive substances were observed in the surface area (Figs 3C and 3E); type II collagen staining with moderate intensity was predominantly present in the central part of the defect and in tissue adjacent to the subchondral bone (Fig. 3G). The repaired tissue was well integrated to adjacent bone and cartilage. Some fissures were present in one defect. Defects B were filled with flat fibrocartilaginous tissue that was horizontally structured with good binding to adjacent tissues (Fig. 3B). Acidic GAGs were present in the upper part of the defect. The intense or moderate PAS positive staining (Fig. 3D and 3F) was observed together with moderate type II collagen staining (Fig. 3H); they were concentrated in the deeper regions of the repaired tissue.

Control group. Two defects were partially filled with chaotic sparse fibrous tissue that revealed both GAG and type II collagen staining negative (Figs 4A and 4B and 4C). The third defect was filled with fibrocartilaginous tissue where some fissures were observed. Moreover, moderate Alcian blue and type II collagen staining were observed in the subchondral bone or in the tissue adjacent to the subchondral bone (Fig. 4 D).

\section{Discussion}

Chondral defects are reported not to regenerate but to be filled by fibrous tissue (Shortkroff et al. 1996). In addition, also treatment of chondral defects with chondroitinase $\mathrm{ABC}$, and fibrin glue containing growth factors resulted in development of fibrous tissue (Hunziker and Rosenberg 1996). On the other hand, osteochondral defects are able to regenerate without treatment by producing a higher amount of proteoglycans, type I and II collagen within six to eight weeks. Later, a decreasing amount of proteoglycans and higher amount of collagen was observed till six months after the operation (Furukawa et al. 1980).

Scaffolds seeded with chondrocytes and cultured in vitro support the production of extracellular matrix by chondrocytes, mainly GAGs, and type II collagen (Pavesio et al. 2003, Trattnig et al. 2005). Our aim was to prepare a scaffold supporting cell proliferation, differentiation, and thus regeneration of the defects.

Heterologous chondrocyte-seeded fibrin implanted into the osteochondral defect in the weightbearing zone was so far reported to repair the defect to a very limited extent. From three weeks after the implantation, many dead cells were observed in the central part of the defects. This was accompanied by 


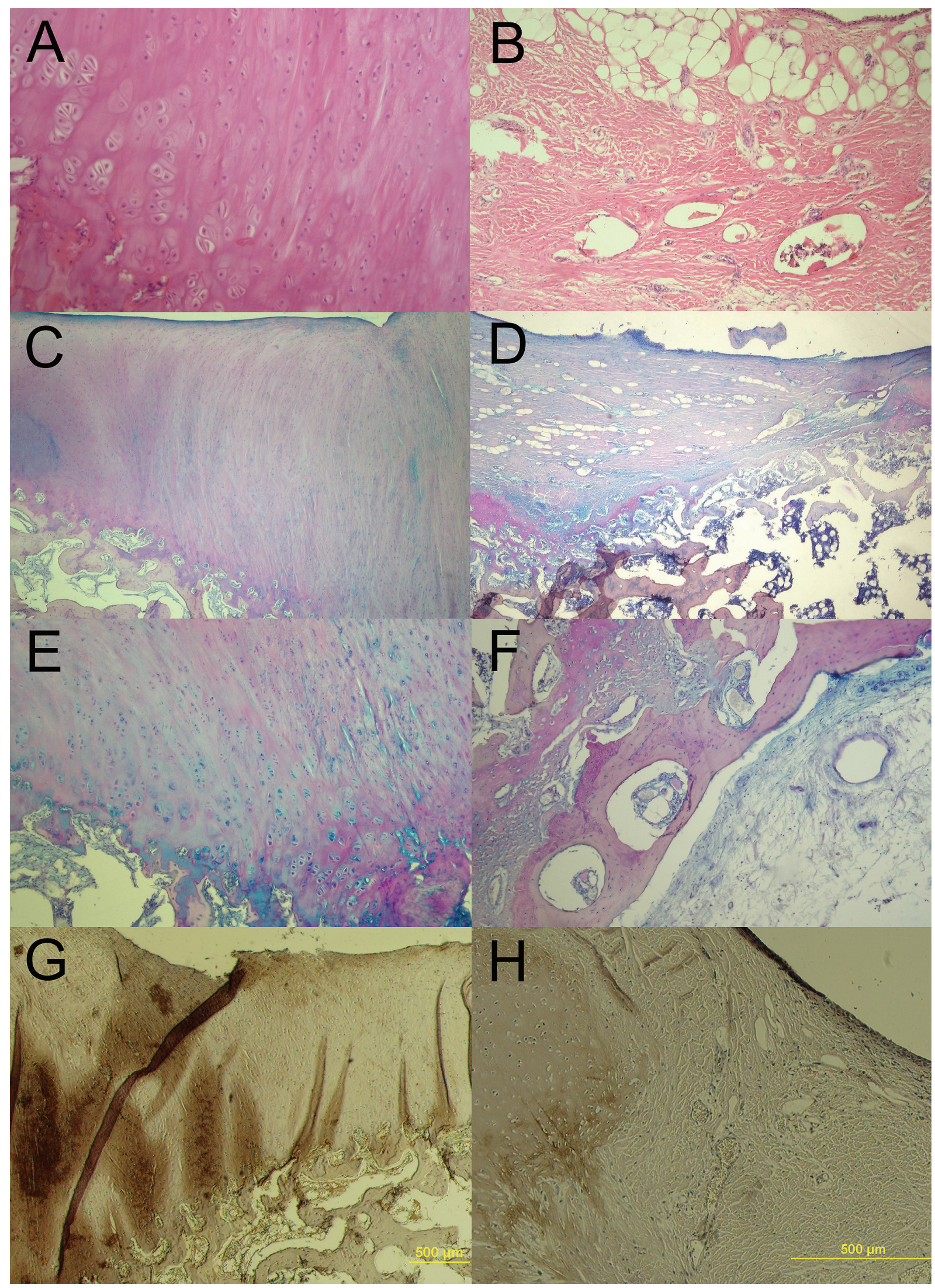

Fig. 2. Histology of osteochondral defects $A(A, C, E, G)$, and defects $B(B, D, F, H)$ of the chondrocyte-seeded scaffold group after 24 weeks using HE staining $(A, B)$, Alcian blue staining and PAS reaction at $\mathrm{pH} 2.5(\mathrm{C}, \mathrm{D}, \mathrm{E}, \mathrm{F})$, and immunohistochemical staining using monoclonal antibody against type II collagen $(G, H)$. Magnification $\times 200(A), \times 100(B, E, F, H), \times 40(D, G)$. 


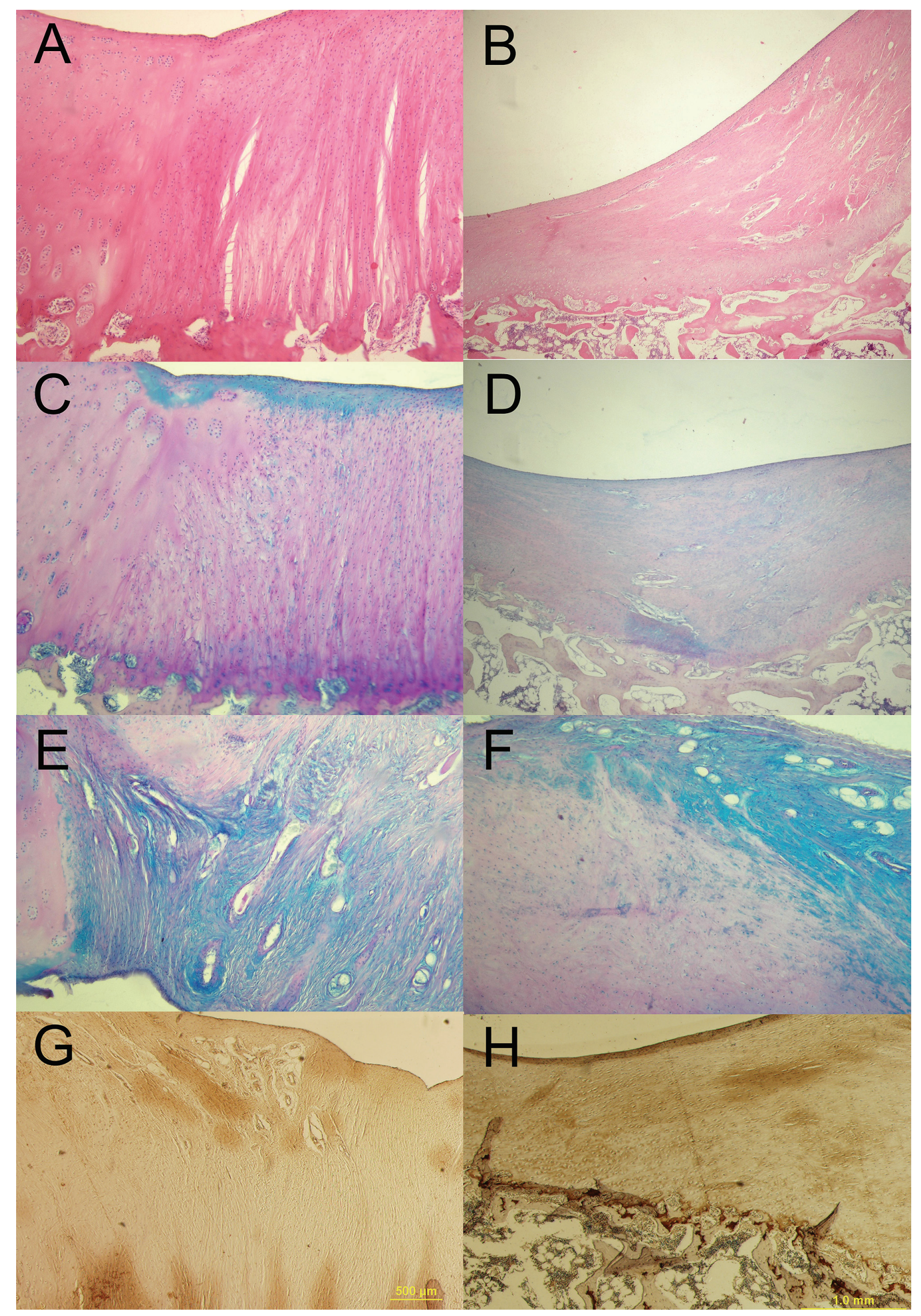

Fig. 3. Histology of osteochondral defects $A(A, C, E, G)$, and $B(B, D, F, H)$ of the non-seeded scaffold group after 24 weeks using $H E$ staining $(A, B)$, Alcian blue staining and PAS reaction at $\mathrm{pH} 2.5(\mathrm{C}, \mathrm{D}, \mathrm{E}, \mathrm{F})$, and immunohistochemical staining using monoclonal antibody against type II collagen $(G, H)$. Magnification $\times 100(A, C, E, F), \times 40(B, D, G, H)$. 


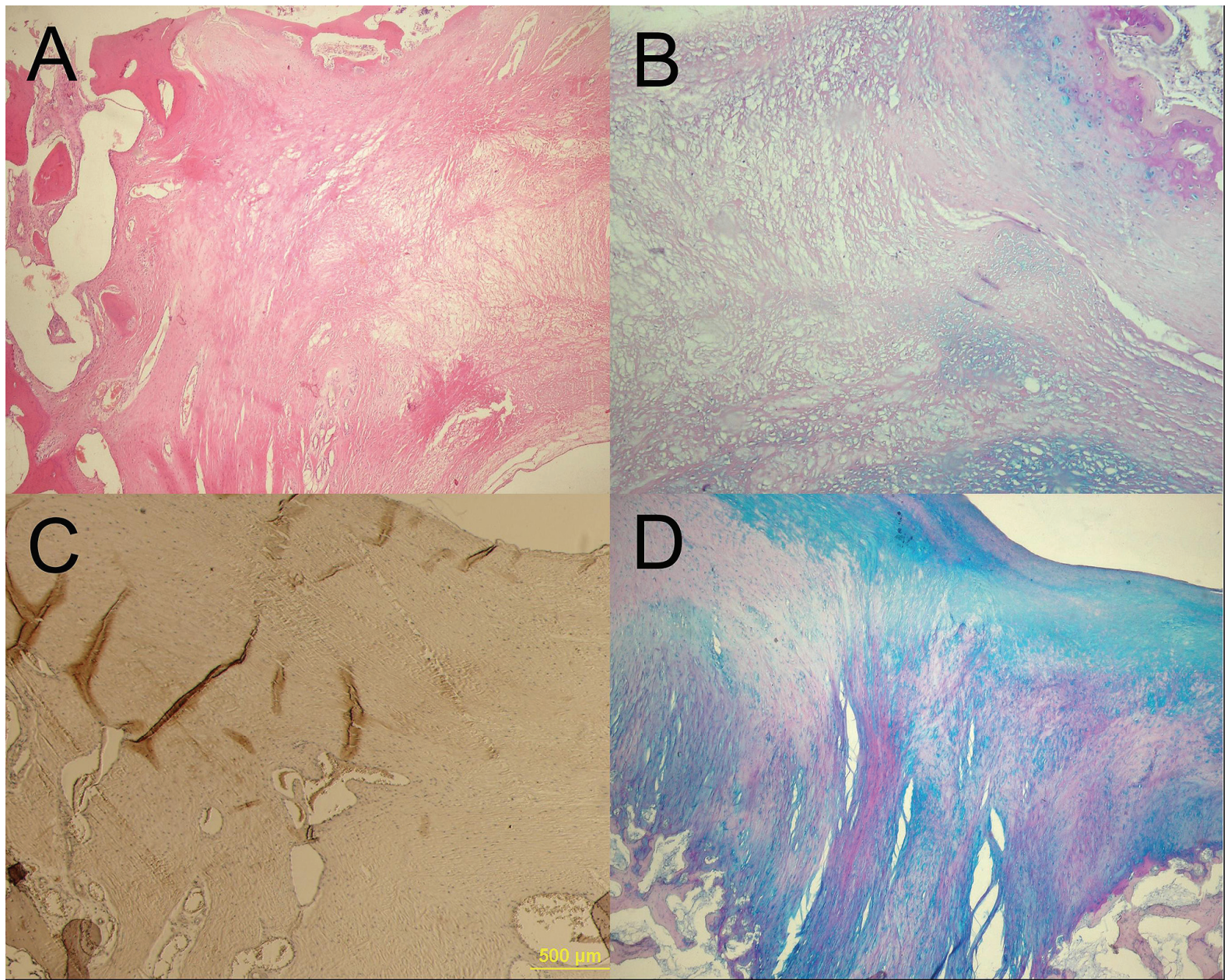

Fig. 4. Histology of osteochondral defects of the control group after 24 weeks using HE staining (A), Alcian blue staining and PAS reaction at $\mathrm{pH} 2.5(\mathrm{~B}, \mathrm{D})$, and immunohistochemical staining using monoclonal antibody against type II collagen (C) which showed chaotic sparse fibrous tissue with negative both GAG and type II collagen staining (A, B, C). Magnification $\times 40(A, C, D), \times 100$ (B).

inflammatory cell migration into progressively degraded fibrin, and subsequently, fibrocartilage formation (van Susante et al. 1999). To improve the biomechanical and biological properties of fibrin, we developed a composite scaffold containing type I collagen, hyaluronic acid, and fibrin. The regenerative potential of the scaffold was already proved in a six-week study in rabbits (data not published yet) where hyaline cartilage was predominantly formed in osteochondral defects. This long-term study proved the healing potential of the method, but also a positive effect of joint loading on regeneration process. Defects A (in the middle of condylus medialis) were located more closely to the weight-bearing zone of the joint. They were subjected to higher passive loading compared to the defects located in the proximal part of femoral trochlea (defects B), while the defects B were primarily subjected to shear stress. In the cell-seeded scaffolds in defects A, regenerated tissue was predominantly filled with hyaline and fibrocartilaginous tissue, while the non-seeded scaffolds formed predominantly fibrocartilage, and defects in the control group contained fibrous tissue. In the cell-seeded group, the hyaline tissue was present predominantly near the base of the lesion and at the borders; fibrocartilage was predominantly found in the central part of the defects, and fibrous tissue was located on the surface. The same distribution of tissue types was observed in ACI treated osteochondral defects three and six months after the implantation (Breinan et al. 2001). Our results are also in accordance with our previous six-week rabbit experiment where the defects were also situated in the non-weightbearing zone of femoral condyle. On the other hand, the repair of the proximal defects was diminished probably due to decreased hydrostatic pressure and increased shear stress. Some hypotheses maintain that shear stress and strain applied to cells result in fibrous tissue formation while compression of the cells by hydrostatic pressure results in hyaline cartilage formation (McMahon et al. 
2004, Kelly and Prendergast 2005).

Interestingly, bioreactor utilizing intermittent pressure and perfusion significantly stimulated both the collagen and GAG synthesis by chondrocytes (Carver and Heath 1999), In contrast, in a spinner flask, the shear stress applied to chondrocytes increased the synthesis of type I collagen, and the fibroblast-like phenotype of chondrocytes at the scaffold periphery (VunjakNovakovic et al. 1999).

In conclusion, the composite scaffold prepared from sodium hyaluronate, type I collagen and fibrin proved its ability to regenerate the osteochondral defect of miniature pigs in a six-month study. The best regeneration of hyaline cartilage and fibrocartilage was observed in the autologous chondrocyte-seeded scaffold group while the non-seeded scaffold group and control group revealed fibrocartilage and fibrous tissue formation, respectively. According to these results we suggest that the novel composite scaffold is promising for treatment of osteochondral defects.

\section{Acknowledgements}

This work was supported by the Grant Agency of AS CR grants No. 1ET400110403 and IAA500390702, the Grant Agency of the Charles University in Prague grants No. 121/2005/B-BIO/2.LF and and the Ministry of Education, Youth and Sport of the Czech Republic grants No. 1M6798582302 and NPV II 2B06130. Internal Grant Agency of the Ministry of Health of the Czech Republic (IGA), grant number: 8122 - 3/2004; Grant Agency of the Czech Republic, grant 304/05/0327; Research Projects, grant numbers: AV0Z50390512 and AV0Z 50110509; We are grateful to Prof. MVDr. František Jelínek, CSc., Dipl. ECVP for the immunohistochemical analysis.

\begin{abstract}
Abbreviations
MRI - magnetic resonance imaging; ACI - autologous chondrocytes implantation; ACT - autologous chondrocytes transplantation; MACT - matrix-associated autologous chondrocyte transplantation; GAG glycosaminoglycan.
\end{abstract}

\section{References}

BREINAN HA, MINAS T, HSU HP, NEHRER S, SHORTKROFF S, SPECTOR M: Autologous chondrocyte implantation in a canine model: change in composition of reparative tissue with time. J Orthop Res 19: 482492, 2001.

BREINAN HA, MINAS T, HSU HP, NEHRER S, SLEDGE CB, SPECTOR M: Effect of cultured autologous chondrocytes on repair of chondral defects in a canine model. J Bone Joint Surg Am 79: 1439-1451, 1997.

BRITTBERG M, LINDAHL A, NILSSON A, OHLSSON C, ISAKSSON O, PETERSON L: Treatment of deep cartilage defects in the knee with autologous chondrocyte transplantation. $N$ Engl J Med 331: 889-895, 1994.

BRYANT SJ, ANSETH KS: Hydrogel properties influence ECM production by chondrocytes photoencapsulated in poly(ethylene glycol) hydrogels. J Biomed Mater Res 59: 63-72, 2002.

BUCKWALTER JA, MANKIN HJ: Articular cartilage: degeneration and osteoarthritis, repair, regeneration, and transplantation. Instr Course Lect 47: 487-504, 1998a.

BUCKWALTER JA, MANKIN HJ: Articular cartilage: tissue design and chondrocyte-matrix interactions. Instr Course Lect 47: 477-486, 1998b.

CARVER SE, HEATH CA: Influence of intermittent pressure, fluid flow, and mixing on the regenerative properties of articular chondrocytes. Biotechnol Bioeng 65: 274-281, 1999.

DRURY JL, MOONEY DJ: Hydrogels for tissue engineering: scaffold design variables and applications. Biomaterials 24: 4337-4351, 2003.

FURUKAWA T, EYRE DR, KOIDE S, GLIMCHER MJ: Biochemical studies on repair cartilage resurfacing experimental defects in the rabbit knee. J Bone Joint Surg Am 62: 79-89, 1980.

HOIKKA VE, JAROMA HJ, RITSILA VA: Reconstruction of the patellar articulation with periosteal grafts. 4-year follow-up of 13 cases. Acta Orthop Scand 61: 36-39, 1990.

HUNZIKER EB, ROSENBERG LC: Repair of partial-thickness defects in articular cartilage: cell recruitment from the synovial membrane. J Bone Joint Surg Am 78: 721-733, 1996.

CHANG CH, LIU HC, LIN CC, CHOU CH, LIN FH: Gelatin-chondroitin-hyaluronan tri-copolymer scaffold for cartilage tissue engineering. Biomaterials 24: 4853-4858, 2003. 
KELLY DJ, PRENDERGAST PJ: Mechano-regulation of stem cell differentiation and tissue regeneration in osteochondral defects. $J$ Biomech 38: 1413-1422, 2005.

KOBAYASHI M, TOGUCHIDA J, OKA M: Preliminary study of polyvinyl alcohol-hydrogel (PVA-H) artificial meniscus. Biomaterials 24: 639-647, 2003.

MARLOVITS S, STRIESSNIG G, KUTSCHA-LISSBERG F, RESINGER C, ALDRIAN SM, VECSEI V, TRATTNIG S: Early postoperative adherence of matrix-induced autologous chondrocyte implantation for the treatment of full-thickness cartilage defects of the femoral condyle. Knee Surg Sports Traumatol Arthrosc 13: 451-457, 2005.

MARLOVITS S, ZELLER P, SINGER P, RESINGER C, VECSEI V: Cartilage repair: generations of autologous chondrocyte transplantation. Eur J Radiol 57: 24-31, 2006.

MCMAHON LA, BARRON V, PRINA-MELLO A, PRENDERGAST PJ: The state-of-the-art in cartilage bioreactors. In: Topics in Bio-Mechanical Engineering. PJ PRENDERGAST and PE MCHUGH (eds), Trinity Centre for Bioengineering \& National Centre for Biomedical Engineering Science, Dublin \& Galway, 2004, pp 94-146.

MINOURA N, KOYANO T, KOSHIZAKI N, UMEHARA H, NAGURA M, KOBAYASHI K-I: Preparation, properties, and cell attachment/growth behavior of PVA/chitosan-blended hydrogels. Mater Sci Engineer: C 6: 275-280, 1998.

NG KW, WANG CCB, MAUCK RL, KELLY T-AN, CHAHINE NO, COSTA KD, ATESHIAN GA, HUNG CT: A layered agarose approach to fabricate depth-dependent inhomogeneity in chondrocyte-seeded constructs. $J$ Orthop Res 23: 134-141, 2005.

NIEDERMANN B, BOE S, LAURITZEN J, RUBAK JM: Glued periosteal grafts in the knee. Acta Orthop Scand 56: 457-460, 1985.

PAVESIO A, ABATANGELO G, BORRIONE A, BROCCHETTA D, HOLLANDER AP, KON E, TORASSO F, ZANASI S, MARCACCI M: Hyaluronan-based scaffolds (Hyalograft C) in the treatment of knee cartilage defects: preliminary clinical findings. Novartis Found Symp 249: 203-217; discussion 229-233, 234-208, 239-241, 2003.

SHORTKROFF S, BARONE L, HSU HP, WRENN C, GAGNE T, CHI T, BREINAN H, MINAS T, SLEDGE CB, TUBO R, SPECTOR M: Healing of chondral and osteochondral defects in a canine model: the role of cultured chondrocytes in regeneration of articular cartilage. Biomaterials 17: 147-154, 1996.

TRATTNIG S, BA-SSALAMAH A, PINKER K, PLANK C, VECSEI V, MARLOVITS S: Matrix-based autologous chondrocyte implantation for cartilage repair: noninvasive monitoring by high-resolution magnetic resonance imaging. Magn Reson Imaging 23: 779-787, 2005.

VAN SUSANTE JL, BUMA P, SCHUMAN L, HOMMINGA GN, VAN DEN BERG WB, VETH RP: Resurfacing potential of heterologous chondrocytes suspended in fibrin glue in large full-thickness defects of femoral articular cartilage: an experimental study in the goat. Biomaterials 20: 1167-1175, 1999.

VUNJAK-NOVAKOVIC G, MARTIN I, OBRADOVIC B, TREPPO S, GRODZINSKY AJ, LANGER R, FREED LE: Bioreactor cultivation conditions modulate the composition and mechanical properties of tissue-engineered cartilage. J Orthop Res 17: 130-138, 1999.

\section{Corresponding author}

E. Filová, Institute of Experimental Medicine, CzAcadSci, Vídeňská 1083, 14220 Prague 4, Czech Republic. E-mail: evafil@biomed.cas.cz 